\title{
Pulmonary Atresia With Ventricular Septal Defects and Major Aortopulmonary Collateral Arteries 18-Year Clinical Experience and Angiographic Follow-up of Major Aortopulmonary Collateral Arteries
}

\author{
Suk-Won Song, MD, PhD; Han Ki Park, MD, PhD*; \\ Young-Hwan Park, MD, PhD*; Bum Koo Cho, MD, PhD**
}

\begin{abstract}
Background: There is no consensus on the long-term outcome after unifocalization in patients undergoing surgery for pulmonary atresia with ventricular septal defects (VSD) and major aortopulmonary collateral arteries (MAPCAs).

Methods and Results: From 1988 to 2006, 40 patients (median age 8.5 months) underwent surgery for pulmonary atresia, VSD, and MAPCAs. The hospital mortality rate for the preparatory procedures was $1.2 \% ; 17$ patients had a complete repair (CR) at a median age of 3 years. Patients with a pulmonary artery index greater than $100 \mathrm{~mm}^{2} / \mathrm{m}^{2}$ had a higher likelihood of CR. The overall survival rate 15 years after first operation in the CR group was $87.5 \%$. Cox analysis demonstrated that increased number of MAPCAs ( $\mathrm{P}=0.019, \mathrm{HR}=1.666$ ) was a significant predictor of poor survival, and $\mathrm{CR}(\mathrm{P}=0.025, \mathrm{HR}=0.141)$ was a significant predictor of favorable prognosis. On angiography, serial measurements of MAPCAs showed a significant decrease in size (from $5.2 \pm 2.9$ to $4.1 \pm 2.9 \mathrm{~mm}$ after a mean of 20 months $)(\mathrm{P}<0.0001)$.

Conclusions: Long-term survival into adulthood can be achieved with an integrated approach. Late survival depends on the number of MAPCAs, and CR. Growth potential of unifocalized MAPCAs was not definite. (Circ J 2009; 73: 516-522)
\end{abstract}

Key Words: Collateral blood flow; Congenital heart disease; Cyanosis

$\mathbf{P}$ ulmonary atresia with ventricular septal defect (VSD) and major aortopulmonary collateral arteries (MAPCAs) is an uncommon form of complex congenital heart disease $!^{-3}$ Until recently, the outcome for patients born with pulmonary atresia, VSD, and MAPCAs was extremely grim, with surgically treated patients having a probability of being alive at age 30 years of only $20 \% 4$. Moreover, there is little evidence that surgical management of these patients resulted in any improvement in their longterm outcomes, with a maximum follow-up of 10 years-7-7

Currently, at our institution children with these lesions are treated using a multistaged repair approach? The operation involves preparatory procedures, consisting of aortopulmonary shunting and unifocalization of the MAPCAs with native pulmonary artery (PA) branches. When reasonable pulmonary vascularization has been obtained, the patients are treated with complete repair $(\mathrm{CR})$ with trans-

(Received April 1, 2008; revised manuscript received August 31, 2008; accepted October 21, 2008; released online January 28, 2009)

Department of Thoracic and Cardiovascular Surgery, Gangnam Severance Hospital, Yonsei University College of Medicine, *Department of Thoracic and Cardiovascular Surgery, Severance Cardiovascular Hospital, Yonsei University College of Medicine and **Health Insurance Review and Assessment Service, Seoul, Republic of Korea Mailing address: Young-Hwan Park, MD, PhD, Division of Cardiovascular Surgery, Severance Cardiovascular Hospital, Yonsei University Health System, 134 Shinchon-dong, Seodaemun-gu, 120-752, Seoul, Republic of Korea. E-mail: yhpark@yuhs.ac

All rights are reserved to the Japanese Circulation Society. For permissions, please e-mail: cj@j-circ.or.jp
Table 1. Patient Clinical Characteristics at First Operation

\begin{tabular}{lc}
\hline \hline No. of patients & 40 \\
\hline Sex (M/F) & $22 / 18$ \\
Age (median, range) & 8.5 months, 6 days-16 years \\
Presenting symptoms & $29(73 \%)$ \\
Cyanosis & $26(65 \%)$ \\
Heart failure & $26(65 \%)$ \\
Cyanosis, heart failure & $75 \pm 13 \%$ \\
Mean arterial oxygen saturation & $14.7 \pm 2.8 \mathrm{~g} / \mathrm{dl}$ \\
Mean hemoglobin & \\
\hline
\end{tabular}

Table 2. Patient Pulmonary Artery Characteristics at First Operation

\begin{tabular}{lc}
\hline \hline No. of patients & 40 \\
\hline Pulmonary artery morphology & \\
I. Moderately hypoplastic & $3(8 \%)$ \\
II. Severely hypoplastic & $19(50 \%)$ \\
III. Absent & $16(42 \%)$ \\
Total no. of MAPCAs/patient & $3.7 \pm 1.5$ \\
Right & $2.1 \pm 1.0$ \\
Left & $1.6 \pm 1.0$ \\
\hline
\end{tabular}

MAPCAs, major aortopulmonary collateral arteries.

Moderately hypoplastic, pulmonary artery index $\geq 60 \mathrm{~mm}^{2} / \mathrm{m}^{2}$; severely hypoplastic, pulmonary artery index $<60 \mathrm{~mm}^{2} / \mathrm{m}^{2}$; absent, no visible central pulmonary artery on angiography.

In the variables of "pulmonary artery morphology", the total number of patients is 38 . In 2 patients, it was difficult to categorize. 
ventricular closure of the VSD and right ventricular outflow tract reconstruction.

The objective of this study was to assess the immediate and long-term outcomes of this multistage approach in 40 pediatric patients with this condition. The main outcomes of interest were immediate and long-term mortality, the proportion achieving $\mathrm{CR}$, rate of surgical reoperation, requirement for postoperative interventional cardiac catheterization, and the functional status of the survivors. We sought to determine risk factors for $\mathrm{CR}$ and unfavorable long-term outcomes. We also sought to evaluate the patency and the growth of unifocalized MAPCAs of these patients by serial angiography.

\section{Methods}

The data of all patients with pulmonary atresia, VSD, and MAPCAs who underwent staged repair at our institution between July 1988 and April 2006 were reviewed. We obtained written informed consent from the caregivers and next of kin of each patient to use their clinical data.

Patients with ductus-dependent pulmonary circulation were excluded from this analysis; 40 patients were offered surgical intervention and constitute the core of this study. Their clinical characteristics and the parameters of PA circulation before the first operation are given in Tables $\mathbf{1}$ and 2 , respectively. PA size was reported as the sum of the cross-sectional areas of the right and left PAs indexed to body surface area, as described by Nakata et al in the patient if there were central PAs. The normal Nakata index is $330 \pm 30 \mathrm{~mm}^{2} / \mathrm{m}^{2}$.

\section{Surgical Techniques}

At our institution, the surgical strategy for these patients consists of performing unifocalization of the MAPCAs through a thoracotomy and a placement of an ipsilateral modified B-T shunt, if possible, with the same procedures performed on the other side during follow-up.

\section{Unifocalization of MAPCAs}

We used an autologous pericardial roll conduit during the early period of this study; however, recently we performed direct anastomosis of the MAPCAs to native PAs, and we preferably connected the modified B-T shunt from the subclavian artery to a native PA.

All collaterals were permanently ligated at their origin, from the aorta. Following ligation, all collaterals were transected and unifocalization was accomplished with tissueto-tissue anastomosis. Collaterals could be anastomosed to other collaterals or to the native PA.

All anastomoses were accomplished using 7-0 Prolene suture (Ethicon, Somerset, NJ, USA). Collaterals were anastomosed as follows.

1. Side-to-side anastomosis of the collateral to the central PAs, thereby augmenting the hypoplastic PAs.

2. Side-to-side anastomosis of collateral to peripheral native PA.

3. End-to-side anastomosis of collateral to collateral or collateral to native PA.

An attempt was always made to bring as many collaterals as possible into as central a location as possible in an attempt to reconstruct a PA confluence.

\section{CR}

Following reasonable pulmonary vascularization,
Table 3. Operative Procedures Performed During the Follow-up Period

\begin{tabular}{lr}
\hline \hline Procedure & $\mathrm{n}$ \\
\hline Preparatory procedures for complete repair & 81 \\
Unilateral modified B-T shunt \& MAPCA unifocalization & 34 \\
Unilateral modified B-T shunt \& MAPCA ligation & 12 \\
Unilateral modified B-T shunt & 10 \\
MAPCA unifocalization & 4 \\
Central shunt & 2 \\
Palliative Rastelli procedure* & 19 \\
Complete repair & 17 \\
Reoperation after complete repair & 6 \\
Total & 104 \\
\hline
\end{tabular}

B-T, Blalock-Taussig. Other abbreviation see in Table 2.

*Right ventricular outflow tract reconstruction without closure of ventricular septal defect.

patients are offered CR. The surgical indication for CR should be on the basis of pulmonary resistance after complete unifocalization, because the postoperative pressure ratio between the right ventricle (RV) and left ventricle (LV) correlates with the risk of surgical death and the longterm outcome, and the number of centrally connected pulmonary arterial segments has been shown to be highly and inversely correlated with pulmonary pressure and resistance in the late period following surgical repair.

We decided to perform definitive repair after thorough discussion with pediatric cardiologists of the morphology of the central PA and development of unifocalized pulmonary arterial beds. Definite repair was tried if the pulmonary arterial bed was relatively well developed, at least 10 lung segments were supplied from an unstenotic pulmonary arterial branch or unifocalized MAPCA, and major pulmonary arterial stenosis was within the range of surgical approach. Cardiopulmonary bypass under moderate hypothermia was begun, the aorta was cross-clamped and cardioplegic solution was given. A longitudinal ventriculotomy was made in the RV infundibulum and resection of hypertrophic muscle bundles was accomplished. The VSD was then closed with a patch. The right atrium was opened to close the atrial septal defect, leaving a small patent foramen ovale. It was elected to leave a patent foramen to function as a "pop-off" valve for systemic venous blood in the event of RV dysfunction or elevated right-sided pressures. At this stage, rewarming commenced and the aortic cross-clamp was released. Pulmonary arterial angioplasty was performed with autologous or bovine pericardium if needed. A connection from the RV to the reconstructed neopulmonary arterial system was performed. The distal conduit was anastomosed to the reconstructed pulmonary arterial confluence. The proximal anastomosis was accomplished and, if necessary, a proximal extension using expanded polytetrafluoroethylene patch (Gore-Tex ${ }^{\circledR}$ Cardiovascular Patch; W. L. Gore \& Associates, Inc, Flagstaff, AZ, USA), or bovine pericardium. The right atrium was then closed. Upon completion of rewarming, the patient was weaned from cardiopulmonary bypass. Transesophageal echocardiography was performed in all patients to assess the integrity of the intracardiac repair, and to obtain an echocardiographic assessment of right-sided pressures. If an intraoperative $\mathrm{RV} / \mathrm{LV}$ pressure ratio $(\mathrm{pRV} / \mathrm{pLV})$ of more than 1.0 is detected after weaning from cardiopulmonary bypass, cardiopulmonary bypass is re-instituted and fenestration of the VSD patch is performed. 
Table 4. Univariate Analysis of Favorable Predictors for CR

\begin{tabular}{|c|c|c|c|c|c|}
\hline & Category & No. of patients & $\begin{array}{c}\text { No. }(\%) \text { of patients } \\
\text { with CR }\end{array}$ & OR $(95 \% \mathrm{CI})$ & $P$ value* \\
\hline \multirow[t]{2}{*}{ Nakata index } & $\geq 100$ & 16 & $10(63)$ & $10.00(1.64-62.50)$ & 0.011 \\
\hline & $<100$ & 14 & $2(14)$ & - & \\
\hline \multirow[t]{2}{*}{ MAPCA unifocalization } & No & 18 & $12(67)$ & $6.80(1.68-27.78)$ & 0.010 \\
\hline & Yes & 22 & $5(23)$ & - & \\
\hline \multirow[t]{2}{*}{ No. of MAPCAs } & $<4$ & 20 & $11(55)$ & $2.85(0.78-10.42)$ & 0.020 \\
\hline & $\geq 4$ & 20 & $6(30)$ & - & \\
\hline
\end{tabular}

CR, complete repair; OR, odds ratio; CI, confidence interval. Other abbreviations see in Table 2.

$* \mathrm{P}<0.05$ was considered significant.

\section{Operative and Postoperative Follow-up Data}

The 40 patients underwent 104 sternotomies and thoracotomies during the study period; these included the preparatory procedures, $\mathrm{CR}$, and reoperation after $\mathrm{CR}$ described in Table 3. The median age at the time of the first operation was 8.5 months (range 6 days to 16 years). Ten patients had only 1 procedure, and the remaining 30 had a mean of $2.4 \pm 1.1$ procedures during the follow-up period. The last follow-up of each patient's clinical status was obtained from their referring pediatric cardiologists or us by telephone interview. Angiograms were reviewed several times to identify the effect of surgical procedures on the growth of the PA and MAPCAs. Because of the diversity of the operations performed, attention was focused on the results of 2 standard procedures: modified Blalock-Taussig shunt and MAPCA unifocalization. When a PA or a unifocalized MAPCA could be identified on serial angiographic examination, its caliber and the size of a $1-\mathrm{cm}$ mark displayed on the grid film at the time of the angiogram were measured. For each patient, care was taken to measure each MAPCA at a similar level devoid of focal stenosis. The absolute size of each vessel was calculated by dividing the measurement of the vessel by the measurement of the 1-cm mark.

\section{Statistical Analysis}

Data were analyzed using SPSS for Windows, version 12.0 (SPSS Inc, Chicago, IL, USA). Categorical variables were compared using the $\chi^{2}$ test or Fisher's exact test, and continuous variables were compared using Student's t-test or Mann-Whitney U-test where appropriate. All analysis were performed not per procedure but per patient. Risk factors favorable for CR were evaluated using stepwise binary logistic regression analysis to estimate the odds ratio (OR) and 95\% confidence interval (CI). Continuous variables were dichotomized using the median or extreme values over the normal range as the cutoff value. A $\mathrm{P}$ value $\leq 0.05$ determined by univariate analysis was chosen as the criterion for submitting variables to the model. Goodnessof-fit was assessed using the Hosmer and Lemeshow $\chi^{2}$ test. The relative risk, defined as the ratio of incidence among the exposed to that among non-exposed subjects, was used to summarize the strength of the association between risk factors and pulmonary complications; the 95\% CI of the relative risk was calculated using Miettinen's test-based approach. Unless otherwise stated, results are expressed as mean \pm standard deviation for continuous variables, and as a percent for categorical variables.

Survival analysis was performed by the Kaplan-Meier method for the whole patient group and separately for those patients who reached CR and those who received "palliative surgery". Survival curves were compared by the log- rank test. A Cox proportional hazards analysis was performed for the same prognostic factors and survival time. The measured PA and MAPCAs diameters were compared with paired t-tests.

\section{Results}

\section{Outcomes}

The in-hospital mortality during the preparatory procedures was $1.2 \%(1 / 81)$. The patient died of aspiration pneumonia 8 days after right-sided modified Blalock-Taussig shunt and MAPCAs unifocalization.

CR was achieved in 17 patients at a median of 16.9 months (range 9 days to 5 years) after the last preparatory procedure. The median age at the time of the repair was 3 years (range 4 months to 15 years). Each repair consisted of transventricular patch closure of the VSD and the placement of a conduit between the ventriculotomy and the main PA. The conduit used was a handmade non-valved tubular graft $(\mathrm{n}=13$, bovine pericardium 6 , bovine pericardium and autologous pericardium 4 , bovine pericardium with polytetrafluoroethylene patch 3$)$, bioprosthetic valved conduit $(n=3)$, and homograft $(n=1)$. In addition, 1 patient had a patch enlargement of both PAs, 1 patient had a patch enlargement of the distal main PA, 2 had patch enlargements of the branched PA, 2 had intraoperative stent insertions into branched PA stenoses, and 1 had an intraoperative balloon angioplasty on the branched PA stenosis. One patient was left with a fenestrated VSD, which was subsequently closed during the same hospital stay ( 9 days after the operation).

Hospital mortality after CR was $11.8 \%$ (2/17). One patient died of respiratory failure, pneumonia, and sepsis. He underwent diaphragm plication because of bilateral diaphragmatic palsy but subsequently went into ventilatory weaning failure 14 months after CR. The other infant died of right heart failure, acute respiratory distress syndrome, and subsequent sepsis on the $8^{\text {th }}$ postoperative day. The mean $\mathrm{pRV} / \mathrm{pLV}$ after CR was $0.57 \pm 0.13$ (range $0.26-0.80$ ).

\section{Favorable Risk Factors for CR}

We assessed various variables for their possible association with CR: age at the time of first operation, body weight, body surface area, arterial oxygen saturation, symptomatic status (cyanosis, congestive heart failure), PA index (Nakata index: summation of cross-sectional area of each PA divided by body surface area, calculated excluding MAPCAs), total number of MAPCAs, preparatory procedures, PA morphology, the presence of confluent PAs, and the performance of MAPCAs unifocalization.

Univariate analysis showed that 3 variables were associated with CR: Nakata index, total number of MAPCAs, and 
Table 5. Multivariate Logistic Regression Analysis of Favorable Predictors for CR

\begin{tabular}{lccccc}
\hline \hline & Category & No. of patients & $\begin{array}{c}\text { No. (\%) of patients } \\
\text { with CR }\end{array}$ & OR (95\%CI) & P value* \\
\hline Nakata index & $\geq 100$ & 16 & $10(63)$ & $10.00(1.64-62.50)$ & 0.011 \\
& $<100$ & 14 & $2(14)$ & - & \\
\hline
\end{tabular}

Abbreviations see in Table 4.

$* \mathrm{P}<0.05$ was considered significant.

A

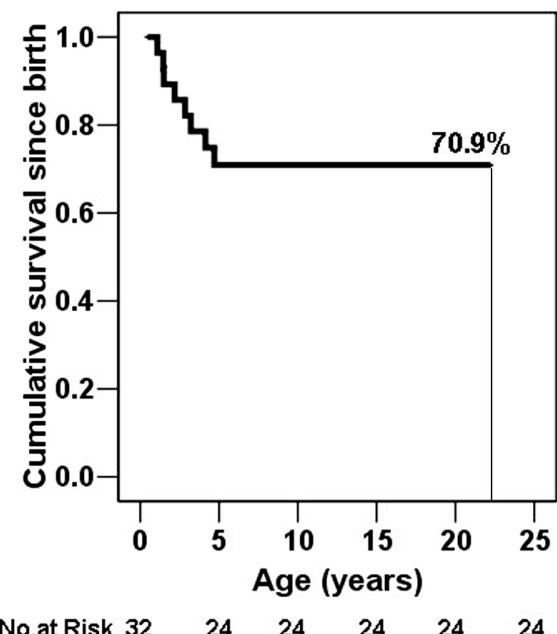

B

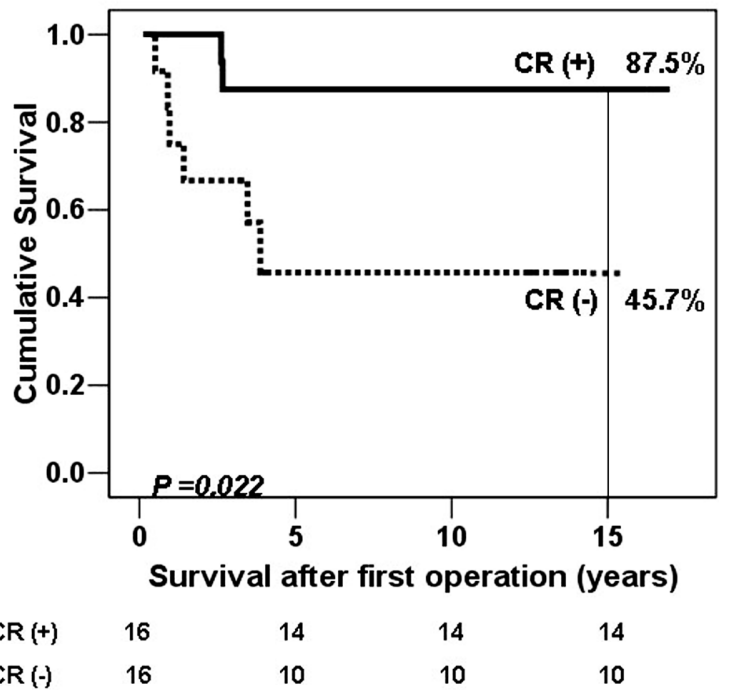

Figure 1. Kaplan-Meier curves of (A) survival since birth of the entire patient cohort, irrespective of ability to undergo complete repair (CR) and (B) survival after the first operation. The latter curves differ significantly between repaired patients and those who remained palliated $(\mathrm{P}=0.022)$.

unifocalization of MAPCAs (Table 4). However, absence of PA was not a risk factor for CR (among 10 patients who did not have a central PA, 3 (30\%) completed definitive repair, whereas among 30 patients who had a central PA, $14(46.7 \%)$ completed definitive repair $(\mathrm{P}=0.427))$.

Stepwise forward binary logistic regression analysis identified a Nakata index of $100 \mathrm{~mm}^{2} / \mathrm{m}^{2}$ or greater as a preoperative variable independently associated with $\mathrm{CR}$ (OR 7.19; 95\%CI 1.09-47.6; $\mathrm{P}=0.013$, Table 5). This result was confirmed using stepwise backward binary logistic regression analysis. The $\chi^{2}$ value for this model was 7.285 for 2 degrees of freedom, indicating that the model was an acceptable fit for the data set.

\section{Follow-up and Long-Term Survival}

Eight patients were lost to follow-up, making the concurrent follow-up rate $80 \%$. The median follow-up time was 54.5 months (range 13.4-205.1 months), for a total of 203.7 patient-years.

The Kaplan-Meier curve for survival since birth of the entire group of patients, irrespective of performance of CR, is shown in Figure 1A. The estimated probability of reaching age 22 years was $70.9 \%$.

Several variables were assessed for association with poor late survival: age at the time of first operation, body weight, body surface area, arterial oxygen saturation, symptomatic status (cyanosis, congestive heart failure), PA index (Nakata index), total number of MAPCAs, preparatory procedures, PA morphology, the presence of confluent PAs, the perfor- mance of MAPCA unifocalization, and CR.

Kaplan-Meier curves of survival after the first operation were significantly different for patients who underwent CR and those who remained palliated $(\mathrm{P}=0.022, \log$-rank test; Figure 1B). After 15 years, the overall survival of the patients was $70.5 \%$.

Cox proportional hazards analysis demonstrated that the total number of MAPCAs, taken as a continuous variable $(\mathrm{P}=0.019$; OR 1.67; 95\% CI 1.088-2.552), and palliative repair $(\mathrm{P}=0.025$; OR 7.09 ; 95\% CI 1.282-39.239) were the only significant factors predictive of poor late survival for each additional month of age.

Five of the 23 patients who did not undergo CR died at a median age of 22 months (range 13 months to 4.7 years). The causes of death were shunt obstruction $(n=1)$ and right heart failure and sepsis $(n=4)$. The remaining palliated patients were still alive after a median of 41.6 months (range 2.6-170.8 months). At last follow-up, 2 patients were in New York Heart Association (NYHA) functional class I, 6 were in class II, and 1 was in class III.

We observed no late deaths, at a median of 60.8 months (range 12 days to 126.4 months) after CR; 80\% (12/15) of patients were in NYHA functional class I, and 1 was in class IV.

Four $(27 \%)$ patients had redo procedures after CR for replacement of the conduit between the RV and the PA. The first replacement of the conduit was performed at a median of 7.3 years (range 2.1-8.5 years) after CR. The freedom from reoperation for conduit replacement is dis- 
A

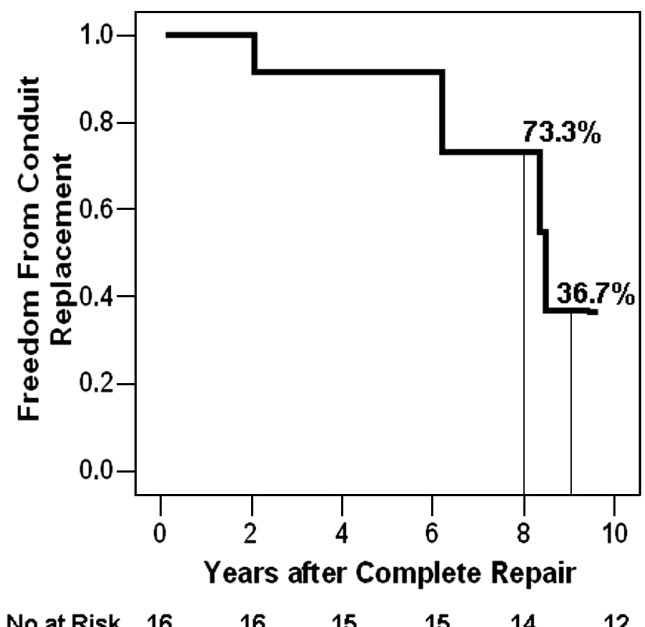

B

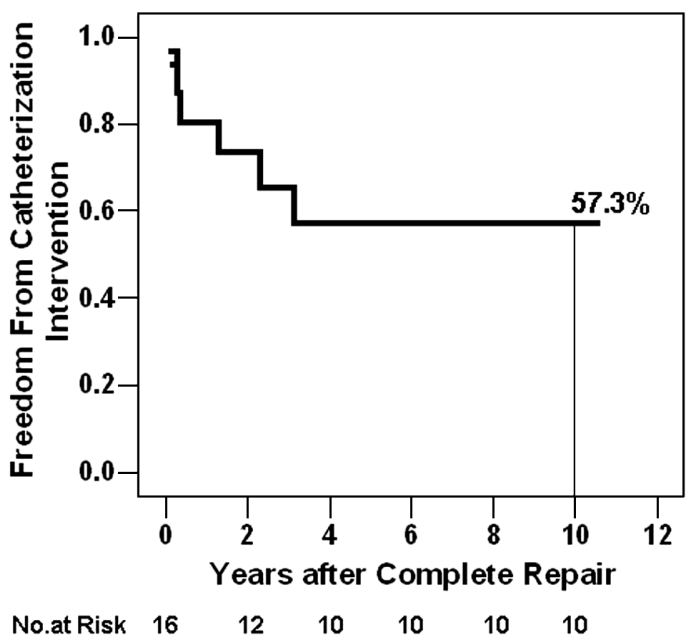

Figure 2. (A) Freedom from reoperation for right ventricle-to-pulmonary artery conduit replacement. (B) Freedom from catheter-based reintervention for pulmonary arteries or major aortopulmonary collateral arteries.
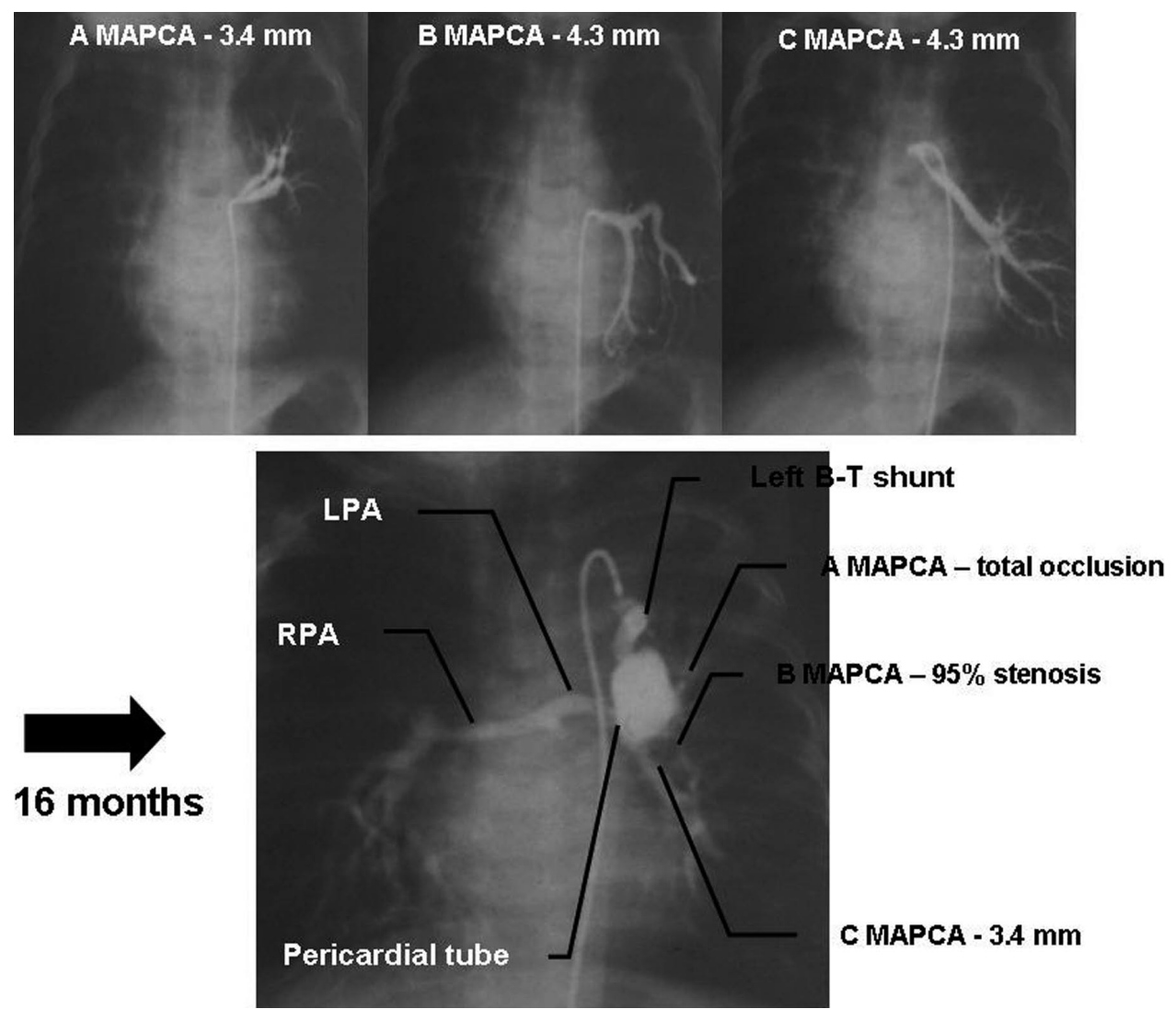

Figure 3. Left major aortopulmonary collateral arteries (MAPCAs) before unifocalization and 16 months after unifocalization. (A) MAPCA with total occlusion from thrombosis, (B) MAPCA with 95\% stenosis, (C) MAPCA reduce in size. B-T, Blalock-Taussig; LPA, left pulmonary artery; RPA, right pulmonary artery.

played in Figure 2A. Six (40\%) patients had re-interventions for branched PAs or MAPCAs at a median of 9.8 months (range 1.0-37.4 months) after CR. The freedom from re-intervention is displayed in Figure 2B.

Fate of Unifocalized MAPCA by Angiographic Evaluation A total of 75 angiograms were reviewed. The effects of the shunt could be evaluated in 14 patients, all of whom had polytetrafluoroethylene shunts. All promoted growth of the central PAs. During the 20-month interval after shunt completion, the diameter of the right PA increased from $6.8 \pm 3.5 \mathrm{~mm}$ to $11.1 \pm 4.5 \mathrm{~mm}(\mathrm{P}=0.012)$ and the diameter of the left PA increased from $7.4 \pm 3.8 \mathrm{~mm}$ to $10.6 \pm 4.4 \mathrm{~mm}$ $(\mathrm{P}=0.018)$. 
A total of 38 unifocalized MAPCAs could be identified on serial angiograms in 17 patients (eg, Figure 3). After a mean of 20 months, 6 had total occlusion with thrombosis, and 5 presented with stenosis greater than $50 \%$. Six of the remaining patients who showed patent unifocalized MAPCAs did not exhibit any growth (from $5.3 \pm 3.2 \mathrm{~mm}$ to $5.2 \pm 3.3 \mathrm{~mm}, \mathrm{P}=0.382$ ). During this period, the body surface area of the patients increased from $0.48 \pm 0.18 \mathrm{~m}^{2}$ to $0.66 \pm$ $0.23 \mathrm{~m}^{2}(\mathrm{P}=0.001)$, while MAPCAs size decreased from $5.2 \pm 2.9 \mathrm{~mm}$ to $4.1 \pm 2.9 \mathrm{~mm}(\mathrm{P}=0.015)$.

\section{Discussion}

This study reports our experience with staged repair for the treatment of children with pulmonary atresia with VSD and MAPCAs. We evaluated the immediate and long-term outcomes of this technique by measuring mortality, the proportion achieving $\mathrm{CR}, \mathrm{pRV} / \mathrm{pLV}$ after $\mathrm{CR}$, surgical reoperation rate, requirement for postoperative interventional catheterization, and the functional status of survivors. We assessed a total of 40 patients with this complex lesion. We found that the overall in-hospital surgical mortality rate was $3.8 \%$ (1/81 preparatory procedures, $2 / 17 \mathrm{CR}, 1 / 6$ reoperation) and the overall 15-year mortality rate was $29.5 \%$ (Figure 1A). CR was attained in $17(42.5 \%)$ patients. The mean $\mathrm{pRV} / \mathrm{pLV}$ after $\mathrm{CR}$ was $0.57 \pm 0.13$. The surgical reoperation rate was $27 \%(4 / 15)$, and 6 patients $(40 \%)$ required additional catheterization-based intervention after CR (Figure 2). Most survivors after CR were in NYHA functional class I symptomatically.

Patients who had undergone $\mathrm{CR}$ had an acceptable mean $\mathrm{pRV} / \mathrm{pLV}$ postoperatively and significant growth of the pulmonary arterial vascular bed at late follow-up. This emphasizes the need to optimize the size of the PA during surgical repair.

We found strong associations between a smaller number of MAPCAs, no need for MAPCA unifocalization, and an adequate PA index with CR. Larger number of MAPCAs, need for MAPCA unifocalization, and an inadequate PA index were all associated with the development of pulmonary vascular obstructive disease in the supplied lung segments.

Our results set a landmark for the expectations of patients with pulmonary atresia, VSD, and MAPCAs-dependent lung circulation who are offered a multistage approach with the goal of CR. We have observed a remarkable improvement in the survival and quality of life among children affected by this condition. Previously, the probability of survival to the age of 30 years was estimated to be $20 \%$, suggesting that surgical intervention may have adversely affected patient outcome. Using our multistage approach, the probability of survival to the age of 22 years was $70.9 \%$. The surgical strategy for pulmonary atresia with VSD and MAPCAs is still controversial. Although sufficient results using the staged approach have been reported, 7-9 the benefits of midline primary repair have also been recently reported $6,10-12$

We found that $42.5 \%$ of our patients achieved CR, which was slightly lower than the rates achieved in other recent reports. Firstly, in our data there seem to be more cases of absent central PA than in the other reports; 16 (42\%) of 38 patients. Ishibashi et al reported that the absence of a central PA was an important risk factor for completion of definitive repair ${ }^{13}$ In our analysis, we included the absence of a central $\mathrm{PA}$ as a variable for completion of definitive repair. Among
10 patients who did not have a central PA, only $3(30 \%)$ completed definitive repair, whereas among 30 patients who had a central PA, $14(46.7 \%)$ completed definitive repair. Although we could not find a statistical difference between the 2 groups $(\mathrm{P}=0.427)$, there was a trend that patients without a central PA did not complete definitive repair. Therefore, if we can analyze a larger number of patients, the absence or presence of a central PA would affect the completion of definitive repair and would be a meaningful risk factor. Second, because this is a retrospective study, so follow-up was not complete ( $80 \%$ follow-up rate). Some patients who underwent palliative surgery and were waiting for $\mathrm{CR}$ might be excluded from the CR group. Despite this lower rate of $\mathrm{CR}$, no late deaths occurred at a median of 103.7 months (range 49.2-205.1 months) after CR, and most of these patients are in NYHA functional class I.

The need for re-intervention with cardiac catheterization or surgical intervention after CR to dilate or occlude vessels and to enlarge PAs or change valve conduits continues to be a problem. In a recent study, patients who had homograft implants and those with bioprosthetic conduits had a freedom from reoperation rate 10 years after CR of $85 \%$ and $43 \%$, respectively ${ }^{14}$ In comparison, we found that the freedom from conduit replacement rate at 8 years was $73.3 \%$ and the freedom from catheter-based intervention at 10 years was $57.3 \%$.

To date, there is no consensus on the long-term fate of MAPCAs, although it has been suggested that growth cannot be obtained from them 14,15 The latter study, however, was based on earlier surgical procedures, and many connections between MAPCAs and native PAs were made by interposing prosthetic material. Those results did not dampen the enthusiasm of surgeons for integrating MAPCAs into the newly reconstructed pulmonary circulation, using various approaches, techniques, and timing. ${ }^{16-19}$ Most of the MAPCA unifocalizations used here were performed through thoracotomies, which are technically easier than through sternotomies, by 2 experienced surgeons (Y. H. Park and B. K. Cho). Despite this ideal setting, the results of unifocalization were disappointing. These are technically demanding operations, accounting for the high rate of thrombosis of these vessels. Even when the MAPCAs remained patent, however, they did not exhibit any growth, which suggests that, at the time of unifocalization, collateral vessels may have already developed maximally. Thus, their integration into the pulmonary circulation would not be associated with any long-term benefit to patients for reaching CR because they likely do not contribute to the definitive lung circulation in repaired patients. In contrast, we found that shunting procedures were extremely efficient in developing even diminutive native pulmonary vascularization.

In a previous report ${ }^{20}$ major aortopulmonary collateral arteries were similar as dilated bronchial arteries. Those researchers concluded that MAPCAs are likely to be dilated bronchial arteries, which may have limited growth potential and their known vasoreactivity might preclude any longterm beneficial effects of the unifocalization procedure. In our serial follow-up angiograms, no growth of MAPCAs was found. We think our results support the results of Norgaard et al. However, we could not completely exclude surgical manipulation of the MAPCAs as the reason for growth failure in the unifocalized MAPCAs. It would be useful to rule out surgical manipulation, if we could analyze the growth pattern of "untouched MAPCAs" on serial angiographic examinations. 
In such a long-term retrospective study, there are inherent limitations. Patients in this cohort who presented for surgical intervention were older than those presenting nowadays, with some perhaps representing survivors of a natural selection process. It is also possible that MAPCAs unifocalized earlier may have better growth potential. Because our results showed a consistent lack of MAPCA growth, however, it is difficult to believe that an earlier procedure would result in potential growth, especially because shunting procedures performed during the same time frame predisposed to the growth of the native vessels. Angiographic identification of MAPCAs is eased by their peculiar morphology, especially unifocalized MAPCAs, with longer tracts before reaching the lungs. Therefore, some MAPCAs unifocalized very distally at the surface of the lung may have better outcomes and could not be identified. Finally, it is likely that patients who underwent angiography at an early time after repair were those who were symptomatic, thus perhaps overestimating PA pressures.

In conclusion, we have shown here that children with pulmonary atresia with VSD and MAPCAs can be successfully treated using a staged repair and that long-term survival into adulthood can be achieved with a multistage approach. In our experience, staged repair yields a relatively low mortality rate with good functional results. There remains room for improvement in the requirement for surgical reoperation. As our experience with this approach has evolved, we have observed significant reductions in associated mortality and morbidity. We anticipate future improvements in quality of life, with reduced need for postoperative surgical and interventional catheterization in patients treated with this approach. In our series, unifocalized MAPCAs exhibited a high incidence of occlusion and no growth.

\section{Acknowledgments}

The authors are grateful to Sung-Yong Park, MD, Sun-Young Sul, RN, and Eun-A Kang, RN, for their valuable contribution to the collection of data in this study.

\section{References}

1. Jefferson K, Rees S, Somerville J. Systemic arterial supply to the lungs in pulmonary atresia and its relation to pulmonary artery development. Br Heart J 1972; 34: 418 - 427.

2. Haworth SG, Macartney FJ. Growth and development of pulmonary circulation in pulmonary atresia with ventricular septal defect and major aortopulmonary collateral arteries. Br Heart J 1980; 44: $14-$ 24.

3. Liao P, Edwards WD, Julsrud PR, Puga FJ, Danielson GK, Feldt RH. Pulmonary blood supply in patients with pulmonary atresia and ventricular septal defect. J Am Coll Cardiol 1985; 6: 1343-1350.

4. Bull K, Somerville J, Ty E, Spiegelhalter D. Presentation and attrition in complex pulmonary atresia. J Am Coll Cardiol 1995; 25: 491-499.

5. Griselli M, McGuirk SP, Winlaw DS, Stumper O, de Giovanni JV, Miller P, et al. The influence of pulmonary artery morphology on the results of operations for major aortopulmonary collateral arteries and complex congenital heart defects. J Thorac Cardiovasc Surg 2004; 127: $251-258$

6. Reddy VM, McElhinney DB, Amin Z, Moore P, Parry AJ, Teitel DF, et al. Early and intermediate outcomes after repair of pulmonary atresia with ventricular septal defect and major aortopulmonary collateral arteries: Experience with 85 patients. Circulation 2000; 101: $1826-1832$.

7. Gupta A, Odim J, Levi D, Chang RK, Laks H. Staged repair of pulmonary atresia with ventricular septal defect and major aortopulmonary collateral arteries: Experience with 104 patients. J Thorac Cardiovasc Surg 2003; 126: 1746-1752.

8. Yagihara T, Yamamoto F, Nishigaki K, Matsuki O, Uemura H, Isizaka $\mathrm{T}$, et al. Unifocalization for pulmonary atresia with ventricular septal defect and major aortopulmonary collateral arteries. J Thorac Cardiovasc Surg 1996; 112: 392-402.

9. Duncan BW, Mee RB, Prieto LR, Rosenthal GL, Mesia CI, Qureshi A, et al. Staged repair of tetralogy of Fallot with pulmonary atresia and major aortopulmonary collateral arteries. J Thorac Cardiovasc Surg 2003; 126: 694-702.

10. Tchervenkov CI, Salasidis G, Cecere R, Beland MJ, Jutras L, Paquet $\mathrm{M}$, et al. One-stage midline unifocalization and complete repair in infancy versus multiple-stage unifocalization followed by repair for complex heart disease with major aortopulmonary collaterals. J Thorac Cardiovasc Surg 1997; 114: 727-735, discussion 735-737.

11. Lofland GK. The management of pulmonary atresia, ventricular septal defect, and multiple aorta pulmonary collateral arteries by definitive single stage repair in early infancy. Eur J Cardiothorac Surg 2000; 18: $480-486$.

12. Murthy KS, Krishnanaik S, Coelho R, Punnoose A, Arumugam SB, Cherian KM. Median sternotomy single stage complete unifocalization for pulmonary atresia, major aorto-pulmonary collateral arteries and VSD-early experience. Eur J Cardiothorac Surg 1999; 16: 21 25.

13. Ishibashi N, Shin'oka T, Ishiyama M, Sakamoto T, Kurosawa H. Clinical results of staged repair with complete unifocalization for pulmonary atresia with ventricular septal defect and major aortopulmonary collateral arteries. Eur J Cardiothorac Surg 2007; 32: $202-208$.

14. d'Udekem Y, Alphonso N, Norgaard MA, Cochrane AD, Grigg LE, Wilkinson JL, et al. Pulmonary atresia with ventricular septal defects and major aortopulmonary collateral arteries: Unifocalization brings no long-term benefits. J Thorac Cardiovasc Surg 2005; 130: 14961502.

15. Sullivan ID, Wren C, Stark J, de Leval MR, Macartney FJ, Deanfield JE. Surgical unifocalization in pulmonary atresia and ventricular septal defect: A realistic goal? Circulation 1988; 78: III-5-III-13.

16. Sawatari K, Imai Y, Kurosawa H, Isomatsu Y, Momma K. Staged operation for pulmonary atresia and ventricular septal defect with major aortopulmonary collateral arteries: New technique for complete unifocalization. J Thorac Cardiovasc Surg 1989; 98: 738-750.

17. Reddy VM, Liddicoat JR, Hanley FL. Midline one-stage complete unifocalization and repair of pulmonary atresia with ventricular septal defect and major aortopulmonary collaterals. $J$ Thorac Cardiovasc Surg 1995; 109: 832-844.

18. Iyer KS, Mee RB. Staged repair of pulmonary atresia with ventricular septal defect and major systemic to pulmonary artery collaterals. Ann Thorac Surg 1991; 51: 65-72.

19. Luciani GB, Wells WJ, Khong A, Starnes VA. The clamshell incision for bilateral pulmonary artery reconstruction in tetralogy of Fallot with pulmonary atresia. J Thorac Cardiovasc Surg 1997; 113: 443452.

20. Norgaard MA, Alphonso N, Cochrane AD, Menahem S, Brizard CP, d'Udekem Y. Major aorto-pulmonary collateral arteries of patients with pulmonary atresia and ventricular septal defect are dilated bronchial arteries. Eur J Cardiothorac Surg 2006; 29: 653-658. 